\title{
Die 6 Interviewfragen
}

\section{Detlev Berning}

Die Interviews sind auf folgende Fragen zugeschnitten und nachträglich darauf konzentriert:

1. Was möchten Sie zu Ihrer Organisation sowie Ihrer Aufgabe erwähnen?

2. Was fällt Ihnen beim Stichwort „Konflikte“ in Ihrer Organisation ein? Was gibt es dazu zu sagen?

3. Was tun Sie in Bezug auf eine positive Organisations- und/oder Konfliktkultur? Was sind Ihre Strategien und Konzepte?

4. Welche Bedeutung messen Sie dabei (zum Thema positive Konfliktkultur) den Führungskräften in Ihrer Organisation bei?

5. Was sind aus Ihrer Sicht die Herausforderungen der nächsten Jahre?

6. Haben Sie Ergänzungen oder Anmerkungen?

D. Berning $(\bowtie)$

Hannover, Deutschland

E-Mail: dr.berning@ berning-hannover.de 